Araştırma Makalesi / Research Article

Makina Mühendisliği /

Mechanical Engineering

DOI: $10.21597 /$ jist.639747
Iğdır Üniversitesi Fen Bilimleri Enstitüsü Dergisi, 10(1): 532-546, 2020

Journal of the Institute of Science and Technology, 10(1): 532-546, 2020

\title{
Design of Unmanned Helicopter Equipped with Turboshaft Engine for Agriculture Spraying Mission Based on Thermodynamic Analysis
}

\section{Selcuk Ekici ${ }^{1 *}$}

\begin{abstract}
In this study, the thermodynamic cycle of a turboshaft engine whose design parameters were determined in accordance with an agricultural spraying unmanned helicopter was performed. After the solid model of the unmanned helicopter was created, a tank was designed to carry additives and water. The design requirements of the turboshaft engine were determined by deciding the maximum power requirement of the unmanned helicopter in accordance with the design parameters of the tank. The performance parameters of each component of the turboshaft engine are presented through diagrams. In addition, entropy generation (exergy destruction) and loop diagrams are presented to the literature depending on performance parameters. This study provides evidence that the design parameters of a manned and/or unmanned helicopter should be considered depending on the environmental conditions. The effect of ambient temperature and pressure varying with altitude on all components of the engine appears as the rate of exergy destruction. Thereby, it is necessary to analyze the ambient temperature and pressure in determining the required design parameters. The relationship of temperature-pressure-entropy production according to the station numbers of the engine is presented through diagrams. It is clearly seen that entropy production increases with the increase in temperature in the components of the turboshaft. Since the aero-vehicle needs maximum power requirements during the take-off phase and its power is associated with temperature, pressure and many other parameters, the take-off phase is an important process in all flight stages.
\end{abstract}

Keywords: Unmanned helicopter, turboshaft, thermodynamic analysis, exergy

${ }^{1}$ Selcuk Ekici (Orcid ID: 0000-0002-7090-3243), Iğdır Üniversitesi, İktisadi ve İdari Bilimler Fakültesi, Havacılık Bölümü, Iğdır, Türkiye

*Sorumlu Yazar/Corresponding Author: Selcuk Ekici, e-mail: selcukekici@gmail.com

Geliş tarihi / Received: 30-10-2019

Kabul tarihi / Accepted: 23-01-2020 


\section{INTRODUCTION}

\section{Underlying Information}

All energy conversion systems in the world are examined by scientists, legislators and researchers due to increasing environmental problems and the danger of decreasing the amounts of global fossil sources. Researchers and scientists have focused their attention on increasing the efficiency of the energy conversion systems by generating more output than the current output value to the fixed input value. Thus they support the reduction of negative factors such as air pollution and climate change by producing more outputs to the same input value. Sectors that have become aware of adverse environmental impacts together with researchers and scientists have examined their energy conversion systems. The aviation sector -both military and commercial aviation- has begun to use different analysis methods to determine the sustainability parameters of various engines equipped with all aircraft. The entire aviation sector has added thermodynamic analysis methods into aero-engine design parameters to develop propulsion systems aimed at decreasing the environmental impact by minimizing the energy consumption of the aircraft-engine pair.

Unmanned aerial vehicles -single rotor, multirotor, fixed wing and hybrid- are now being used in all sectors and thus deserve to be the subject of all researches. Unmanned aerial vehicles (UAVs) perform many different missions in various sectors. For this reason, various studies in the literature have described different missions to UAVs. Outstanding issues in the researches carried out in order to perform UAVs duties in the sector are as follows in the literature; to analyze urban traffic (Salvo et al., 2014), site detection and heritage management in archaeological survey projects (Stek, 2016), automated asphalt pavement inspection (Zakeri et al., 2016), forest monitoring (Zhang et al., 2016), to investigate patterns of tiger and prey poaching (Aziz et al., 2017), to image textile evidence at crime scenes (Bucknell and Bassindale, 2017), to monitor forest health during a simulated disease outbreak (Dash et al., 2017), for safety inspection on construction sites (De Melo et al., 2017), to monitor and to manage pedestrian traffic (Sutheerakul et al., 2017), to analyze vegetation (Senthilnath et al., 2017), suitable site selection of dam construction, to model farmland topography (Ajayi et al., 2018), inspection of mobile cranes (Belmonte, 2018), detection of buried archaeological remains (Calleja et al., 2018), reducing CO2 emissions, delivery (Goodchild and Toy, 2018), mixing of biochemical samples (Katariya et al., 2018), monitoring of solar photovoltaic power plants (Kumar et al., 2018), photogrammetry (Langhammer et al., 2018), lake imaging and monitoring (Liardon et al., 2018), to estimate forest structural attributes (Liu, 2018), microwave tomography radar imaging (Ludeno et al., 2018), to monitor and detect for atrisk persons (Iuga et al., 2018), applications in the built environment, building inspection (Rakha and Gorodetsky, 2018), to determine Rapid melting dynamics of an alpine glacier (Rossini et al., 2018), to map river landscape (Rusnák et al., 2018), bridge inspection (Seo et al., 2018), trajectory tracking (Singha et al., 2018), to map an earthquake-induced landslide (Valkaniotis et al., 2018), crop growth information collection (Wang et al., 2018), building model reconstruction (Zheng et al., 2018), to monitor vegetated terrain (Akturk and Altunel, 2019), aerial imaging of vineyard crops (Andújar et al., 2019), volcano monitoring (De Beni et al., 2019), detecting 'poachers' with drones (Hambrecht et al., 2019), mapping for archaeology (Hill, 2019), to determine how conservation management programs and techniques have affected herbicide use and distribution (Malone and Foster, 2019), to transport medical equipment (McCall, 2019), soil salinity assessment of cropland (Ivushkin et al., 2019), the detection and monitoring of marine fauna (Verfuss et al., 2019), to control bird damage to wine grapes (Wang et al., 2019), monitoring vessels in emission control areas (Xia et al., 2019). 


\section{Earlier Researches}

In the open literature, the thermodynamic analysis is employed to provide a detailed map of the design, performance, optimization and environmental parameters of turbomachines due to the development of aerial vehicle and industry. The articles where performance parameters of turboshaft engines are reported using the thermodynamic analysis are listed as follow by year; Aydin et al. (2012), perform thermodynamic analysis through data obtained from an experimental turboshaft/turboprop engine at various power settings. They state that the aero engine, which is the subject of the study, is a turboprop engine and can also be used in helicopters as a turboshaft engine and present exergetic performance parameters of the engine to the literature by means of thermodynamic analysis. The results obtained from the study are important for understanding the operating conditions of propeller aircraft and helicopters under different loads. Turan and Aydın (2016), employ thermodynamic analysis to obtain detailed information about a turboshaft engine and its components used in helicopter applications. The study demonstrates a thermodynamic analysis on the basis of energy and exergy. They state that the turboshaft engine, which is the subject of the analysis, is used for both military and civilian purposes. They suggested that energy and exergy-based analysis of turboshaft engines would be useful in the design of future rotary-wing aircraft. Coban et al. (2017), investigate the performance parameters of a military helicopter engine via thermodynamic analysis and present the exergy destruction rates of the engine components to the literature by calculating the energy and exergy amounts of turboshaft engine under different loads. Components exergy destruction rates are determined under $284 \mathrm{Nm} 436 \mathrm{Nm} 547$ $\mathrm{Nm} 579 \mathrm{Nm}$ load values of the engine, respectively. Turboshaft engine data are obtained from the experiments carried out at the level where the test rig was set up. They also examined the turboshaft engine performance parameters in terms of the relative exergy destruction, the fuel depletion ratio, the efficiency lack, the improvement potential. Koruyucu (2019), investigates the electric hybridization of a turboshaft engine used as a power system in light helicopters. Koruyucu also developed a parallel hybrid system by incorporating an electric motor into a light-duty helicopter equipped with a turboshaft engine and examined the energy and exergy parameters of the helicopter under the maximum power setting. In addition, there are articles in the open literature where analyses of other aeronautics and astronautics engines, except turboshaft engines, are carried out (Şöhret, 2018a; Şöhret 2018b).

The motivation of this study is to apply the thermodynamic analysis to determine the design parameters of a turboshaft engine that can be equipped with an unmanned helicopter (UH) designed for use in agricultural spraying. The contributions of the study to the literature are as follows;

(i) Demonstration of turboshaft engine selection according to the requirements (mission type, payload, volume, power setting, maximum take-off weight etc.) determined in the study.

(ii) Presentation of a helicopter engine pair whose requirements are determined according to a specific mission.

\section{MATERIAL AND METHODS}

\section{The First Law Equations}

The thermodynamic analysis of turbomachinery is carried out assuming that it operates under steady-state steady-flow (SSSF) process. In the first law of thermodynamics defined as energy conservation, enthalpies of energy conversion system components expressed as the sum of internal energy, flow energy, kinetic and potential energy. Energies rate of change can be defined as (Arntz, 2014); 


$$
\nabla \cdot\left(\rho \delta h_{i} \boldsymbol{V}\right)=\nabla \cdot(\rho \delta e \boldsymbol{V})+p_{\infty} \nabla \cdot \boldsymbol{V}+\nabla \cdot\left(p-p_{\infty}\right) \boldsymbol{V}+\nabla \cdot\left(\rho \frac{V^{2}}{2} \boldsymbol{V}\right)
$$

Clearly writing the energy flow from the environment to the control volume and/or from the control volume to the environment for a steady-state steady-flow process is shown in Eq 2 (Dincer and Rosen, 2012);

$$
\dot{Q}_{\text {in }}+\dot{W}_{\text {in }}+\sum \dot{m}_{\text {in }}\left[h_{\text {in }}+\frac{V_{\text {in }}^{2}}{2}+g z_{\text {in }}\right]=\dot{Q}_{\text {out }}+\dot{W}_{\text {out }}+\sum \dot{m}_{\text {out }}\left[h_{\text {out }}+\frac{V_{\text {out }}^{2}}{2}+g z_{\text {out }}\right]
$$

\section{Entropy}

Entropy presenting the difference between reversible and irreversibility is the concept proving that non-theoretical cycles of energy conversion systems will take place in one direction (Eq. 3).

$$
d S \geq \frac{d Q}{T}
$$

The entropy change obtained using the relationship between entropy, the specific heat at constant pressure and gas constant is shown in Eq. 4.

$$
d s=c_{p} \frac{d T}{T}-R \frac{d P}{P}
$$

\section{Isentropic Relations, Speed of Sound, Stagnation properties}

The relationship between pressure and temperature at the inlet and outlet of the energy conversion system components can be defined as follows (Mattingly, 2006);

$$
R \int_{P_{\text {in }}}^{P_{\text {out }}} \frac{d P}{P}=c_{p} \int_{T_{\text {in }}}^{T_{\text {out }}} \frac{d T}{T}
$$

The speed of sound is expressed by the following Eq. 6;

$$
a=-\rho \frac{d a}{d \rho}
$$

Speed of sound for perfect gas is expressed as follow;

$$
a^{2}=\frac{d P}{d \rho}=\frac{d\left(c \rho^{y}\right)}{d \rho}
$$

Eq. 8, 9, 10 are described the stagnation temperature, stagnation pressure and stagnation density relationship in terms of the Mach number, respectively (Mattingly, 2006).

$$
\begin{gathered}
\frac{T_{t}}{T}=1+\frac{\gamma-1}{2} M^{2} \\
\frac{P_{t}}{P}=\left(1+\frac{\gamma-1}{2} M^{2}\right)^{\frac{\gamma}{\gamma-1}} \\
\frac{\rho_{t}}{\rho}=\left(1+\frac{\gamma-1}{2} M^{2}\right)^{\frac{1}{\gamma-1}}
\end{gathered}
$$




\section{Exergy Equations}

Based on the definition of Marmolejo-Correa and Gundersen (2012), the temperature-based (thermo) part of physical exergy is shown in Eq. 11 and the pressure-based (mechanical) part of physical exergy is shown in Eq. 12.

$$
\begin{gathered}
\dot{E} x_{p h}^{T}=\dot{m}\left[\left(h\langle T, p\rangle-h\left\langle T_{0}, p\right\rangle\right)-T_{0}\left(s\langle T, p\rangle-s\left\langle T_{0}, p\right\rangle\right)\right] \\
\dot{E} x_{p h}^{p}=\dot{m}\left[\left(h\left\langle T_{0}, p\right\rangle-h\left\langle T_{0}, p_{0}\right\rangle\right)-T_{0}\left(s\left\langle T_{0}, p\right\rangle-s\left\langle T_{0}, p_{0}\right\rangle\right)\right]
\end{gathered}
$$

Chemical exergy of a gas mixture is described as follow;

$$
\overline{e x}_{c h}=\sum_{i=1}^{j} y_{i} \overline{e x}_{c h, i}+\bar{R}_{u} T_{0} \sum_{i}^{j} y_{i} \ln y_{i}
$$

\section{FRAMEWORK}

\section{Unmanned Helicopter Design Parameters}

Unmanned aerial vehicles can fly unaccompanied by the onboard existence of pilot and are either ground-controlled or autonomously operated during the duty flight (Narayanan et al., 2015). Therefore, it is used in many applications today. The unmanned aerial vehicle that the subject of this study is an autonomous helicopter. The unmanned helicopter is designed for use in agriculture spraying. The solid model design of the unmanned helicopter is shown in Fig. 1a, 1b. Fig. 1a is shown a side view of UH and Fig. $1 \mathrm{~b}$ is shown the isometric view of UH. The maximum take-off power of the unmanned helicopter designed for spraying agricultural is estimated at $1500 \mathrm{~kW}$. The UH, which is equipped with a tank, is assumed to have a pesticide carrying capacity of 42 liters (Fig. 2). The radius and height of the 42 liters tank are $15 \mathrm{~cm}$ and $60 \mathrm{~cm}$ respectively. The wall thickness is $2 \mathrm{~cm}$.

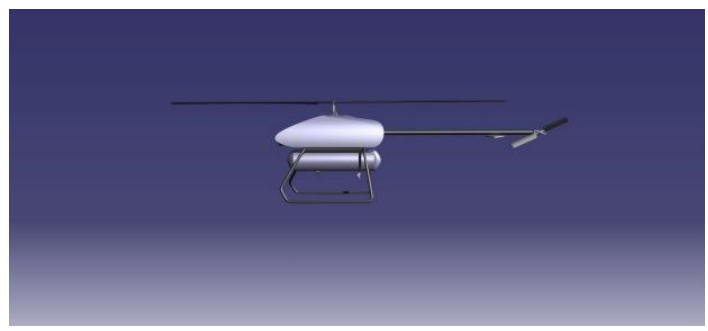

(a)

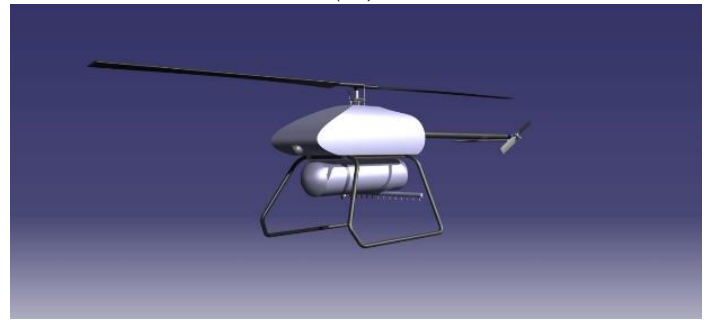

(b)

Figure 1. The solid model design of agricultural spraying UH: (a) side view, (b) isometric view.

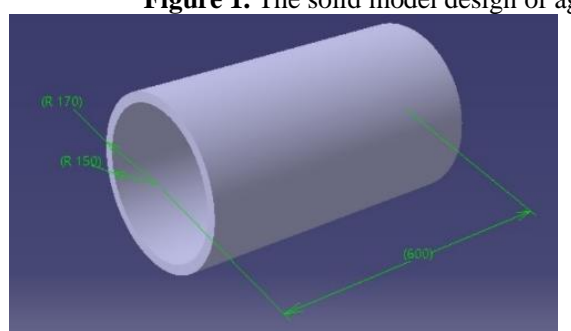

(a)

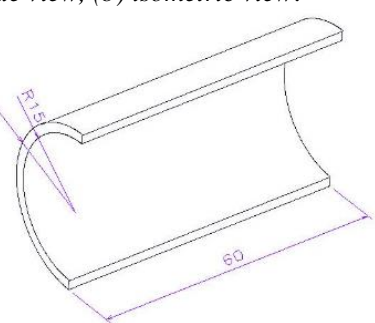

(b)

Figure 2. Dimensioning and schematic solid model of spraying tank (a) solid model, (b) section. 


\section{Turboshaft Engine Design Requirements and Assumptions}

The equipment of the unmanned helicopter equipped with a tank, which will be used for agricultural spraying, also includes a turboshaft engine. Cycle parameters of turboshaft engine, which was designed for UH and thermodynamically analyzed, were generated through GasTurb 12 software. Schematic illustration of the turboshaft engine of agricultural spraying UH is shown in Fig. 3. The illustrative representation of the turboshaft engine includes the station numbers of the engine. 2, 3, 31, 4, 41, 5, 6 and 8 describe air inlet, compressor exit, burner inlet, burner exit, stator outlet, turbine exit, exhaust path and exhaust, respectively. In the design of turboshaft engine, the cooling ratio of the nozzle guide vane component (NGV) that is located between the outlet of the combustion chamber and the inlet of the turbine in turboshaft engines is accepted as $8.75 \%$. The task of NGV is to guide the combustion product flow out of the combustion chamber and ensure that it enters the turbine properly. Since NGV is exposed to very high temperatures, it must be cooled continuously. Therefore the cooling of the NVG component of the agriculture spraying UH's engine was considered $8.75 \%$. In addition, the cooling ratio of high-pressure turbine (HPT) was designed as $1.25 \%$.

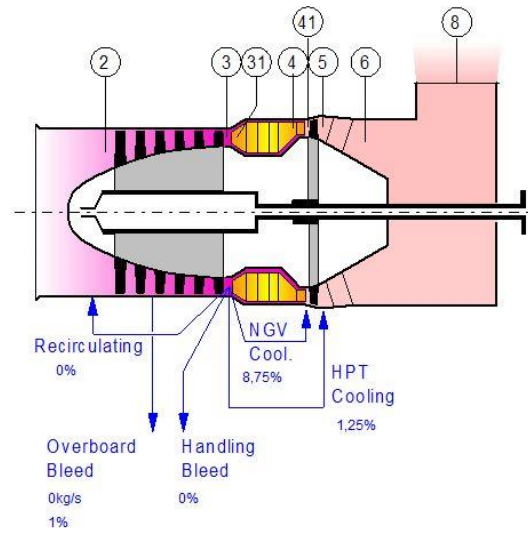

Figure 3. Schematic representation of turboshaft engine designed for agricultural spraying $\mathrm{UH}$.

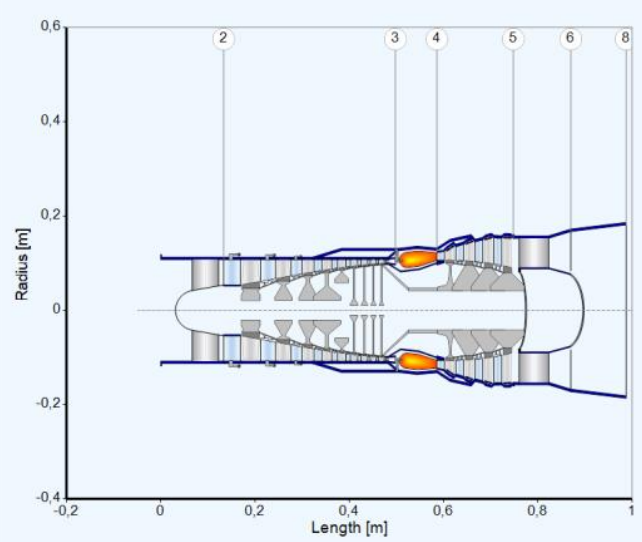

Figure 4. Dimensioning the engine with design requirements.

The design requirements and assumptions of the turboshaft engine are listed in Table 1. Thermodynamic performance parameters of the unmanned helicopter were calculated at maximum power requirement at sea level. Since the maximum power requirements of aircraft are under takeoff operation mode, the unmanned helicopter modelled at takeoff flight phase. The throttle level setting must be at the maximum for the turboshaft engine to reach maximum power. In addition, the airflow rate required for the combustion reaction, the fuel type and the fuel heating value are listed in Table 1 . Since the modelling was carried out at sea level, the ambient temperature and pressure were determined as $288.15 \mathrm{~K}$ and $101.325 \mathrm{kPa}$, respectively. The characteristics of the overall turboshaft engine and the local characteristics of the engine components are listed in Table 1. Dimensioning the engine with design requirements is shown in Fig. 4. See also Fig. 4 is shown the length and radius within the station numbers of the engine. 
Table 1. The design requirements and assumptions of the turboshaft engine.

\begin{tabular}{|c|c|c|}
\hline $\begin{array}{r}\text { Altitude } \\
\text { Flight phase } \\
\text { Power setting } \\
\text { Mass flow corrected to standard day conditions } \\
\text { Inlet pressure ratio } \\
\text { Pressure ratio } \\
\text { Burner exit temperature } \\
\text { Burner design efficiency } \\
\text { Fuel heating value } \\
\text { Fuel type } \\
\text { Mechanical efficiency } \\
\text { Burner pressure ratio } \\
\text { Exhaust pressure ratio }\left(P_{8} / P_{a m b}\right) \\
\text { Shaft power delivered } \\
\text { Ambient temperature } \\
\text { Ambient pressure } \\
\text { Compressor tip speed } \\
\text { Compressor inlet radius ratio } \\
\text { Compressor inlet Mach number } \\
\text { Number of stages for compressor } \\
\text { Number of stages for turbine }\end{array}$ & $\begin{array}{c}\mathrm{kW} \\
\mathrm{K} \\
\mathrm{kPa} \\
\mathrm{m} / \mathrm{s}\end{array}$ & $\begin{array}{l}\text { at sea level } \\
\text { take-off (maximum power } \\
\text { requirement) } \\
\text { at maximum throttle } \\
5.2 \\
0.99 \\
12 \\
1450 \\
0.99 \\
43.124 \\
\text { JP-8 } \\
0.99 \\
0.97 \\
1.03 \\
1511.7 \\
288.15 \\
101.325 \\
330 \\
0.5 \\
0.54 \\
9 \\
4\end{array}$ \\
\hline
\end{tabular}

\section{RESULTS AND DISCUSSIONS}

In this study, the turboshaft engine was modelled based upon data obtained from the design requirements of software for an agriculture spraying duty flight. In this part of the research, the results of the design requirements and the thermodynamic analysis of the results are presented.

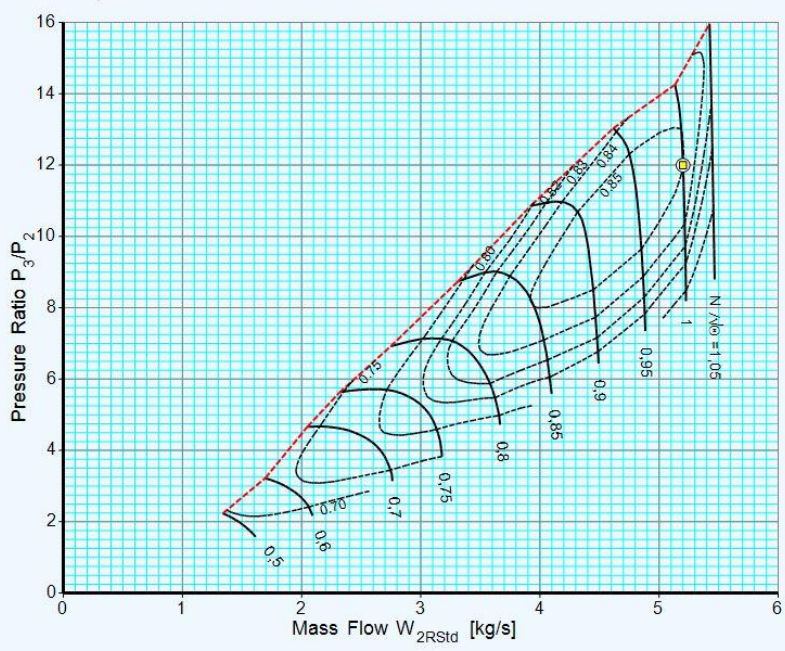

Figure 5. Axial compressor map generated by GasTurb 12 software.

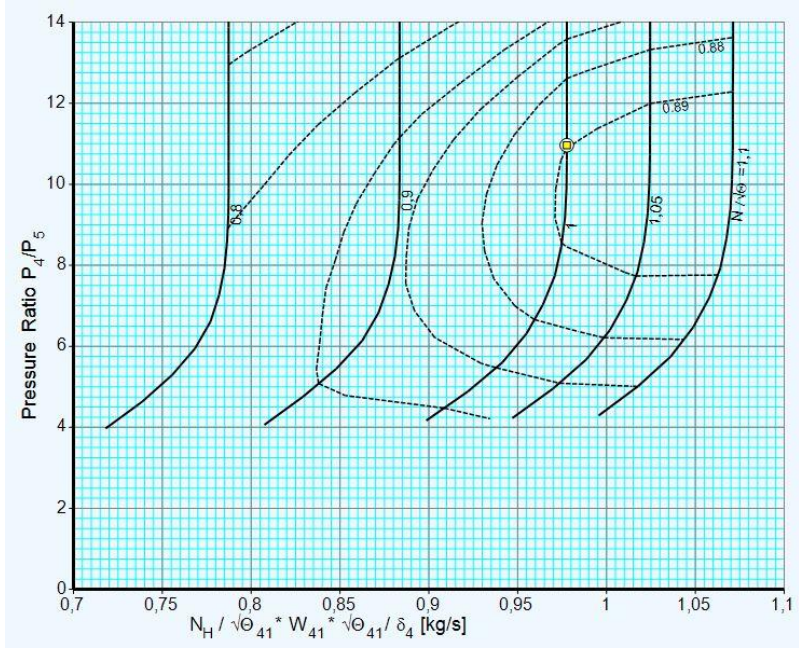

Figure 6. Turbine map generated by GasTurb 12 software.

The compressor pressure ratio-mass flow graph is given in Fig. 5. Axial compressors map is generated by the software. The yellow square shown in the circle is shown the requirements of the 
designed turboshaft engine on the compressor map. In other words, the compressor map point which is suitable for turboshaft engine problem definition of the unmanned helicopter to be used for agricultural spraying is given in Fig. 5. See also Fig. 5 is given an idea of what the turbine design map should look like through the compressor map. Point of attention on the compressor map is the effect of the air mass flow on the compression ratio. The density of the air decreases as the air temperature increases due to the inverse ratio between air density and temperature. Due to the decrease in air density, it will cause a decrease in the air mass flow entering the compressor. The effect is manifested by slowing down the compressor and reducing the pressure ratio. Compressor achieves a lower pressure ratio by slowing down its velocity to compensate for the lower mass flow. Compressor efficiency is not greatly affected by the low-pressure ratio and velocity drop due to air temperature rise. Therefore, the compressor pressure ratio and air mass flow rate to be selected in the design stage are important location on the compressor map. The turbine map generated by the software is shown in Fig. 6. Although the graph of the turbine map is different from the compressor map, the behavior of the turbine is approximately similar. Increasing the inlet temperature of the turbine requires less mass flow to produce the same power rate of the turbine. Therefore, the turbine rotates at the same velocity as the compressor. Because it is connected to the compressor via a shaft. If a deceleration occurs in the compressor, it will be felt in the turbine. As a result, the turbine map of the agriculture spraying unmanned helicopter was obtained as shown in Fig. 6. The volume and pressure relationship of the mass flows through the components of the designed turboshaft engine is shown in Fig 7. The diagram also is shown the station numbers of the engine. The path from point 2 to point 3 defines the pressure-volume change of the airflow through the compressor. The path from point 3 to point 4 is shown for the combustion chamber and 4-5 describes the relationship between pressure-volume in the turbine. The total temperature and pressure values at the inlets and outlets of the components are shown graphically in Fig. 8. In the graph, the total temperature is expressed in yellow squares per station. The total pressure is indicated by a plus sign in blue. Considering the total pressure, the pressure loss in the combustion chamber is seen between stations 3 and 4. Many studies in the literature have addressed pressure loss in the combustion chamber (Roth and Mavris, 2000; Lefebvre and Ballal, 2010; Boyce, 2012; Şöhret et al., 2015; Coban et al., 2017). When the total temperature is taken into consideration, the temperature increase due to the compression between the compressor inlet and outlet can easily be read from the graph (Şöhret et al., 2015; Coban et al., 2017).

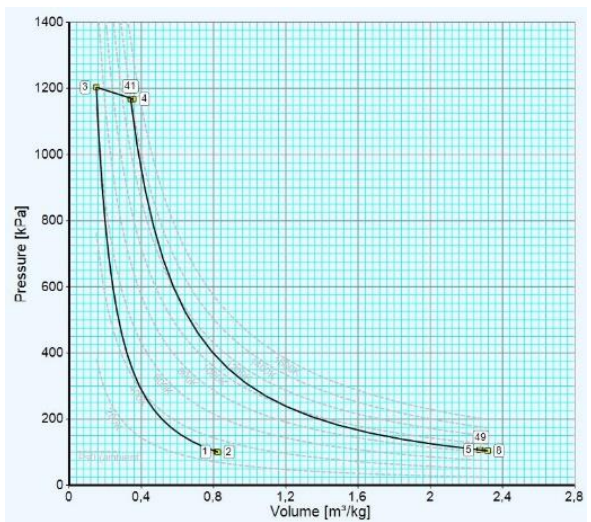

Figure 7. Pressure-volume diagram of turboshaft engine operating at maximum load.

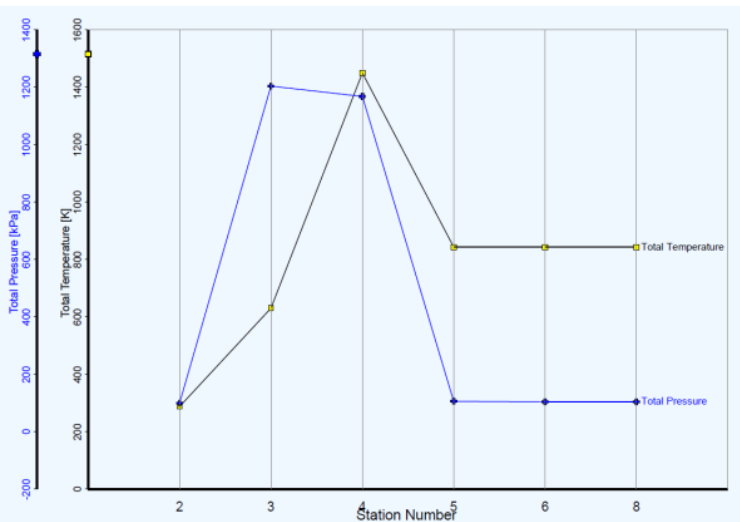

Figure 8. Total temperature and total pressure values according to the station numbers of the engine. 


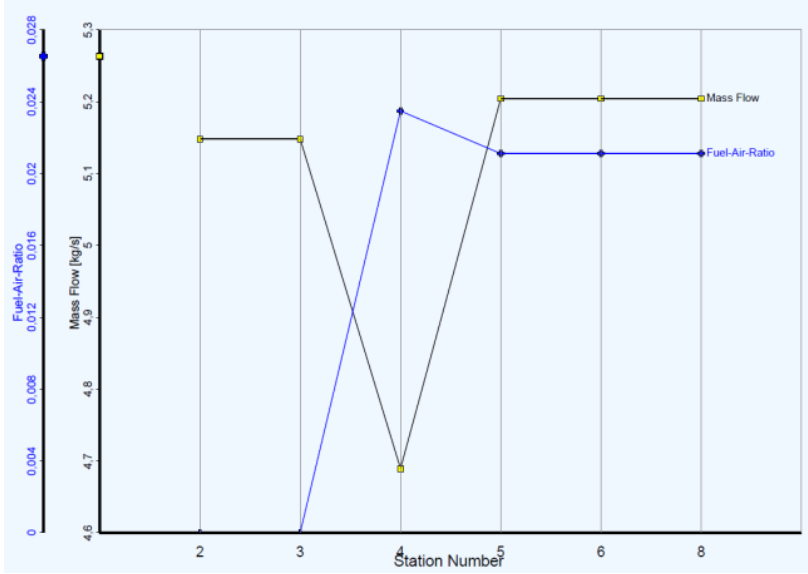

Figure 9. Fuel-air ratio and mass flow diagrams according to the station numbers of the engine.

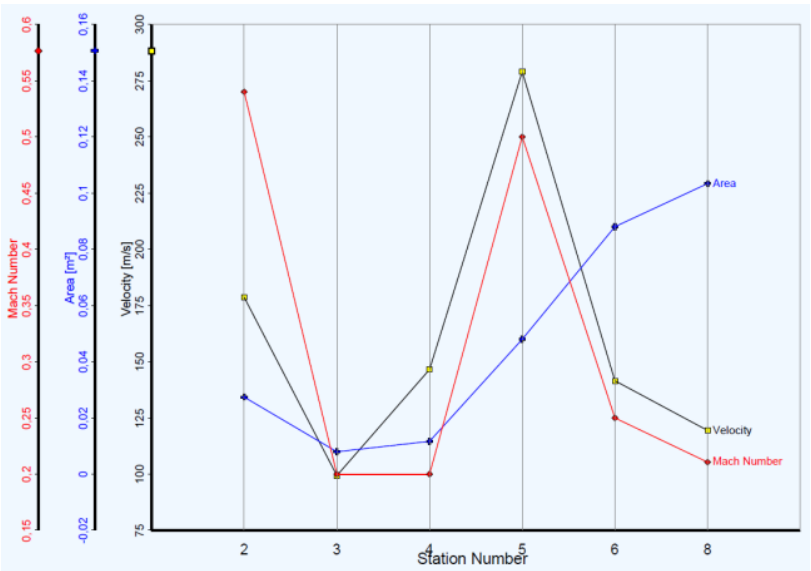

Figure 10. Velocity, area and Mach number diagrams according to the station numbers of the engine.

Fuel-air ratio and mass flow diagrams according to the station numbers of the engine are shown in Fig. 9. In the diagram, the yellow squares show the mass flow rates passing through the stations, and the blue plus sign indicate the fuel-air ratio across the station. When mass flows are evaluated based on components, the following results are obtained. Airflow through the compressor is constant. Due to the separation of cooling air at the compressor outlet, Less air than the air entering the compressor at the inlet of the combustion chamber is available. Although the air in the combustion chamber is blending with fuel, a mass flow less than the mass flow at the compressor inlet progressively decreases along the combustion chamber. Decreasing progressively of the mass flow through the combustion chamber is an indication that the cooling air is being withdrawn from the component. At the exit of the combustion chamber, there is now the mass flow of the combustion products. The increase of the mass flow at the turbine inlet is due to the addition of cooling air. According to the law of conservation of mass, the flow of combustion products at the turbine outlet must be greater than the mass flow of air at the compressor inlet. This excess is clearly seen in the diagram. Throughout the remaining stations, the mass flow rates of combustion products are constant (Igwe, 2019; Kilani et al., 2019). When the fuel-air ratio is evaluated based on the components, the following results are obtained for Fig. 9. Since the fuel flow is not present at the compressor inlet and outlet, the fuel-air ratio is not available. An increase in the fuel-air ratio occurs due to fuel spraying throughout the combustion chamber. Both the increase in the fuel flow and the separation of some air from the airflow for cooling starting from the inlet of the combustion chamber increases the fuel-air ratio in the combustion chamber. The remarkable point occurs in the turbine. Fuelair ratio decreases throughout the turbine. The increase in the fuel-air ratio in the turbine is due to the fact that the cooling air is included in the flow to increase the total airflow rate. The fuel-air ratio is constant in the remaining parts of the turboshaft engine (Krishnan, et al., 2018; Sanaye et al., 2018).

Velocity, area and Mach number diagrams according to the station numbers of the engine are shown in Fig. 10. In Fig. 10, the yellow, blue, and red marks show the speed, area, and Mach number, respectively. It is seen that the velocity along the compressor decreases considering the stations marked with yellow color in the diagram. It is seen that the velocity increases between 3-4 and 4-5. Looking at the curve drawn with blue color, it was observed that the area increased in all the remaining components starting from the turbine. When the Mach number is examined, it is observed that the Mach number decreases throughout the compressor. The reason for the decrease in the Mach number in the compressor is the increase in the static pressure by decreasing the dynamic pressure. In the turbine, the number of Mach increases along the turbine. The dynamic pressure of the combustion products increases and the 
static pressure decreases in the turbine. At the same time, the change of the Mach number in both the compressor and the turbine is understood by the velocity curve drawn in yellow. The increase in the velocity causes to increase the dynamic pressure and the decrease in the velocity causes to decrease the static pressure (Kaya et al., 2016).

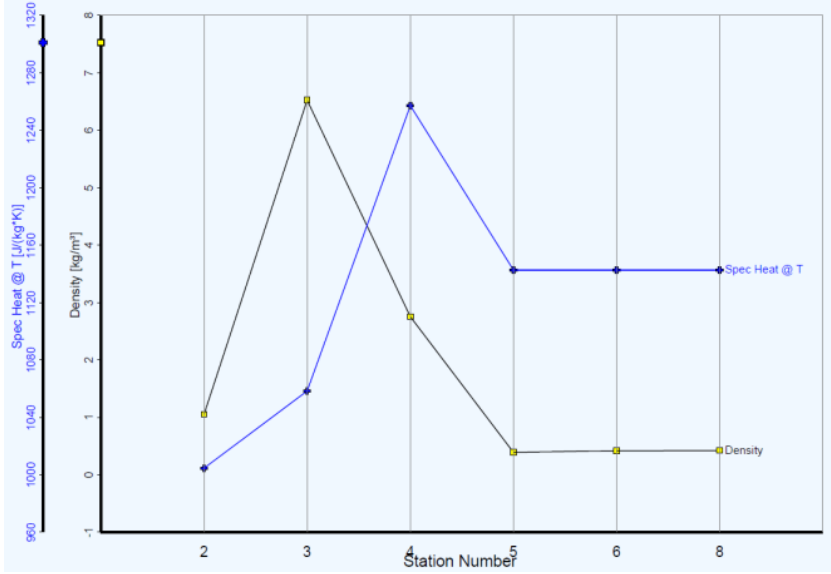

Figure 11. Specific heat capacity and density diagrams according to the station numbers of the engine.

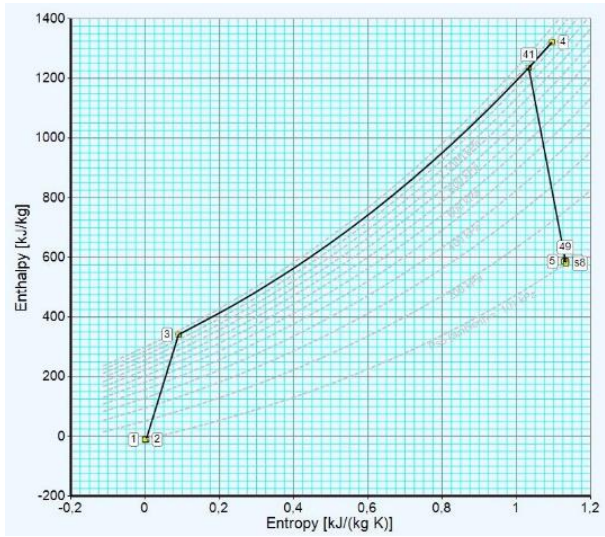

Figure 13. Diagram of enthalpy-entropy relationship according to the station numbers of the engine.

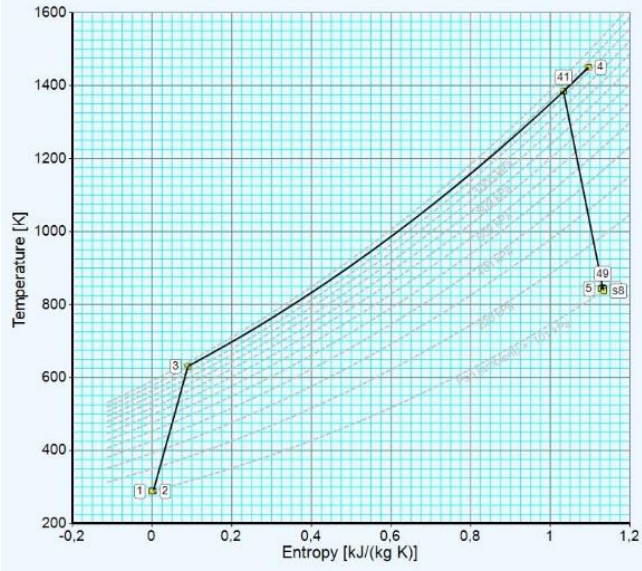

Figure 12. Diagram of temperature-entropy relationship according to the station numbers of the engine.

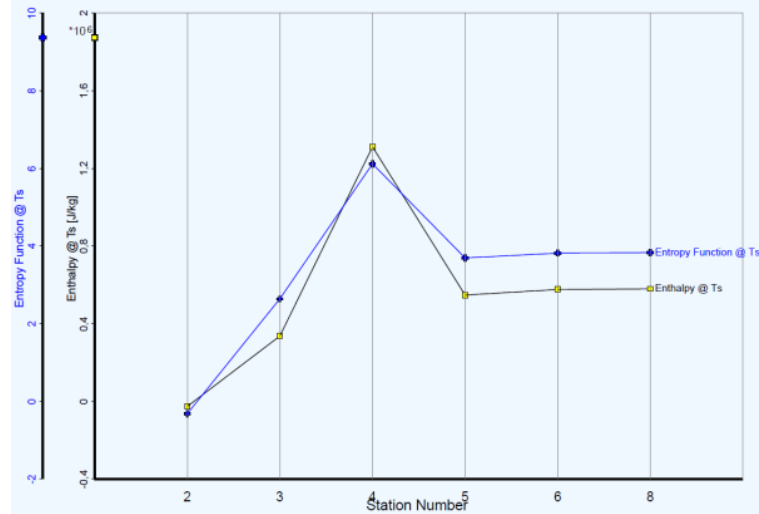

Figure 14. Enthalpy and entropy generation rates according to the station numbers of the engine.

Specific heat capacity and density diagrams according to the station numbers of the engine are shown in Fig. 11. The density diagram is highlighted in yellow and the specific heat capacity diagram is marked in blue. When the density curve is taken into consideration, the increase in the density of the air due to the compression in the compressor and the decrease in the density of the combustion products due to the expansion of the turbine can be seen from the graph. Changes in the specific heat capacity are a function of temperature, hence change rates increase with rising temperature. The specific heat capacity is highest at the turbine inlet or combustion chamber outlet. In addition, the highest density value occurs at the compressor outlet.

Diagram of temperature-entropy generation relationship according to the station numbers of the engine is shown in Fig. 12. It is clearly seen that entropy generation increases with the rising at the temperature in turboshaft's components. It is understood from the temperature-entropy loop that the component with the highest increase in entropy generation is the combustion chamber. The loop diagram also shows that the highest rate of exergy destruction (known as exergy generation) occurs in the 
combustion chamber. One of the mistakes made when performing the thermodynamic analysis of turbomachinery is the reduction of entropy in the turbine. It is evident from Fig. 12 that the total entropy production will always be positive despite the decrease in temperature in the turbine (expansion process).

Diagram of enthalpy-entropy relationship and enthalpy and entropy generation rates according to the station numbers of the engine are shown in Fig. 13 and Fig. 14, respectively. The enthalpy-entropy relationship is presented as an engine-loop diagram. The grid of enthalpy in the loop presents the work produced in the turbine and the rate of work the compressor needs. Therefore, back work ratio of the turboshaft engine and the amount of power required for the cockpit (lighting, ventilation, etc.) are easily obtained from the graph. Enthalpy and entropy generation rates are indicated by yellow color and blue color respectively in Fig. 14.

Exergy rates according to the station numbers of the engine are indicated in Fig. 15. Exergy rate at the compressor input called the station 2 is zero as can be seen from the graph. Since the air enters the compressor at ambient temperature and ambient pressure, the exergy rate of station 2 is zero. In addition, the amount of chemical exergy (function of temperature and pressure) caused by different gases in the air is negligible. Exergy rate increases throughout the compressor. The increase in the temperature and pressure of the air caused by the compression process in the compressor has led to an increase in the compressor output exergy rate. The highest rate of exergy occurred in the combustion chamber. The reason for the highest amount of exergy in the combustion chamber is the fuel chemical exergy. The rate of exergy decreases due to decreasing temperature and pressure at the turbine outlet.

In this study where turboshaft engine selection is made for agricultural spraying, all thermodynamic performance parameters of the engine designed by the software are presented in Figure 5-15. In addition, the results of the engine design requirements are listed in Table 2. Temperature and pressure values at component inlet/outlet are shown divided into static and dynamic values in Table 2. Also, various efficiencies of components are seen in Table 2.

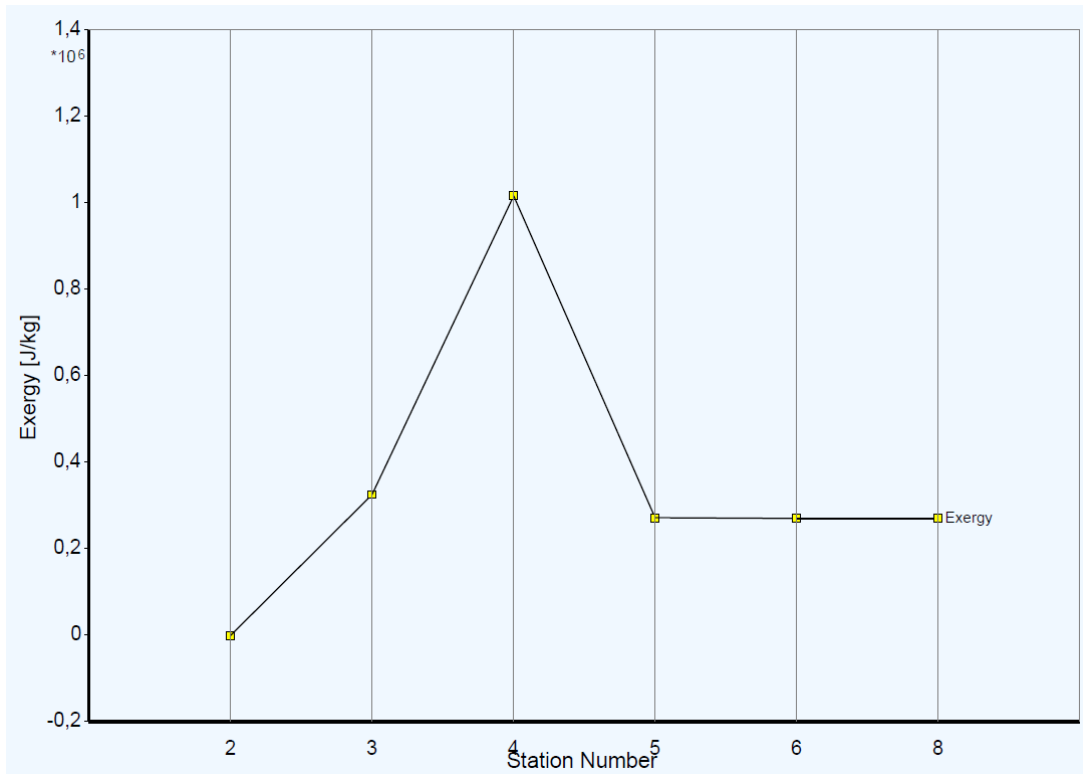

Fig. 15. Exergy rates according to the station numbers of the engine. 
Design of Unmanned Helicopter Equipped with Turboshaft Engine for Agriculture Spraying Mission Based on Thermodynamic Analysis

Table 2. Results of engine design requirements.

\begin{tabular}{|c|c|c|c|c|c|c|c|c|}
\hline Station & Flow rate & & Temperature (K) & \multicolumn{2}{|c|}{ Pressure (kPa) } & \multicolumn{3}{|c|}{ Corrected mass flow $(\mathrm{kg} / \mathrm{s})$} \\
\hline Ambient & - & & 288.15 & & 101.325 & \multicolumn{3}{|c|}{-} \\
\hline 1 & 5.148 & & 288.15 & & 101.325 & \multicolumn{3}{|c|}{-} \\
\hline 2 & 5.148 & & 288.15 & & 100.312 & \multicolumn{3}{|c|}{5.2} \\
\hline 3 & 5.148 & & 630.42 & & 1203.741 & \multicolumn{3}{|c|}{0.641} \\
\hline 31 & 4.582 & & 630.42 & & 1203.741 & \multicolumn{3}{|c|}{-} \\
\hline 4 & 4.689 & & 1450 & & 1167.629 & \multicolumn{3}{|c|}{0.913} \\
\hline 41 & 5.140 & & 1384.39 & & 1167.629 & \multicolumn{3}{|c|}{0.978} \\
\hline 5 & 5.204 & & 843.14 & & 106.495 & \multicolumn{3}{|c|}{8.470} \\
\hline 6 & 5.204 & & 843.14 & & 104.365 & \multicolumn{3}{|c|}{-} \\
\hline 8 & 5.204 & & 843.14 & & 104.365 & \multicolumn{3}{|c|}{8.643} \\
\hline Bleed & 0.051 & & 630.42 & & 1203.733 & \multicolumn{3}{|c|}{-} \\
\hline Efficiencies & Isentropic & \multicolumn{2}{|r|}{ Polytropic } & & Power & \multicolumn{3}{|c|}{$1511.7 \mathrm{~kW}$} \\
\hline Compressor & 0.85 & \multicolumn{2}{|r|}{0.89} & & PSFC & \multicolumn{3}{|c|}{$0.2562 \mathrm{~kg} /(\mathrm{kWh})$} \\
\hline Turbine & 0.89 & \multicolumn{2}{|c|}{0.85} & & Thermal eff. & \multicolumn{3}{|c|}{0.3259} \\
\hline Mechenical & 0.99 & \multicolumn{2}{|c|}{-} & & Fuel flow & \multicolumn{3}{|c|}{$0.10757 \mathrm{~kg} / \mathrm{s}$} \\
\hline & & Units & St 2 & St 3 & St 4 & St 5 & St 6 & St 8 \\
\hline \multicolumn{2}{|c|}{ Static temperature } & $\mathrm{K}$ & 272.25 & 625.78 & 1441.46 & 809.15 & 834.39 & 836.91 \\
\hline \multicolumn{2}{|c|}{ Static pressure } & $\mathrm{kPa}$ & 82.26 & 1171.27 & 1137.81 & 90.38 & 100.11 & 101.33 \\
\hline \multirow{2}{*}{\multicolumn{2}{|c|}{$\begin{array}{r}\text { Velocity } \\
\text { Mach number }\end{array}$}} & \multirow[t]{2}{*}{$\mathrm{m} / \mathrm{s}$} & 178.63 & 99.32 & 146.54 & 278.91 & 141.49 & 119.37 \\
\hline & & & 0.54 & 0.2 & 0.2 & 0.5 & 0.25 & 0.21 \\
\hline \multicolumn{2}{|c|}{$\begin{array}{r}\text { Mach number } \\
\text { Density }\end{array}$} & $\mathrm{kg} / \mathrm{m}^{3}$ & 1.053 & 6.520 & 2.750 & 0.390 & 0.418 & 0.421 \\
\hline
\end{tabular}

\section{CONCLUSIONS}

In this study, the thermodynamic cycle of a turboshaft engine whose design parameters were determined in accordance with an agricultural spraying unmanned helicopter was performed. In addition, the component-based performance parameters of the turboshaft engine required for the application of the spraying duty were determined based on the maximum power requirement at the sea level. The conclusions conducted from this study are as follows;

Entropy generation reaches its highest value in the combustion chamber component of the turboshaft engine. In other words, the presence of the highest exergy destruction is found in the combustion chamber. An improvement in the combustion chamber of the turboshaft engine during the design phase may reduce the amount of exergy destruction. Information about entropy generation can be obtained by changing the design parameters without being involved in any production and motor testing process. But the irreversibility process belongs to the nature of the combustion reaction.

This study provides evidence that the design parameters of a manned and/or unmanned helicopter should be considered depending on the environmental conditions. The effect of ambient temperature and pressure varying with altitude on all components of the engine appears as the rate of exergy destruction. Thereby, it is necessary to analyze the ambient temperature and pressure in determining the required design parameters. Since the aero-vehicle needs maximum power requirements during the take-off phase and its power is associated with temperature, pressure and many other parameters, the take-off phase is an important process in all flight stages.

Particularly for designers, it would be beneficial to optimize the motor design requirements according to the thermodynamic analysis results. Optimizing by exergy can be performed by identifying the connections of each design requirement to other design requirements.

E. Further studies can be compared with theoretical design data by testing with an engine to be designed by producing an unmanned helicopter prototype capable of performing the spraying task in case of support. 


\section{REFERENCES}

Ajayi OG, Palmer M, Salubi AA, 2018. Modelling farmland topography for suitable site selection of dam construction using unmanned aerial vehicle (UAV) photogrammetry. Remote Sensing Applications: Society and Environment, 11, 220-230.

Akturk E, Altunel A.O, 2019. Accuracy assesment of a low-cost UAV derived digital elevation model (DEM) in a highly broken and vegetated terrain. Measurement, 136, 382-386.

Andújar D, Moreno H, Bengochea-Guevara J., de Castro A, Ribeiro A, 2019. Aerial imagery or on-ground detection? An economic analysis for vineyard crops. Computers and electronics in agriculture, 157, 351358.

Arntz A, Atinault O, Merlen A, 2014. Exergy-based formulation for aircraft aeropropulsive performance assessment: theoretical development. AIAA Journal, 53(6), 1627-1639.

Aydin H, Turan O, Karakoc TH, Midilli A, 2012. Component-based exergetic measures of an experimental turboprop/turboshaft engine for propeller aircrafts and helicopters. International Journal of Exergy, 11(3), 322-348.

Aziz MA, Tollington S, Barlow A, Goodrich J, Shamsuddoha M, Islam MA, Groombridge JJ, 2017. Investigating patterns of tiger and prey poaching in the Bangladesh Sundarbans: Implications for improved management. Global Ecology and Conservation, 9, 70-81.

Belmonte N, Staulo S, Fiorot S, Luetto C, Rizzi P, Baricco M, 2018. Fuel cell powered octocopter for inspection of mobile cranes: Design, cost analysis and environmental impacts. Applied energy, 215, 556-565.

Boyce MP, 2012. Gas Turbine Engineering Handbook, 4nd ed., Elsevier.

Bucknell A, Bassindale T, 2017. An investigation into the effect of surveillance drones on textile evidence at crime scenes. Science \& justice, 57(5), 373-375.

Calleja JF, Pagés OR, Díaz-Álvarez N, Peón J, Gutiérrez N, Martín-Hernández E, ... Álvarez, PF, 2018. Detection of buried archaeological remains with the combined use of satellite multispectral data and UAV data. International journal of applied earth observation and geoinformation, 73, 555-573.

Coban K, Colpan CO, Karakoc TH, 2017. Application of thermodynamic laws on a military helicopter engine. Energy, 140, 1427-1436.

Coban K, Şöhret Y, Colpan CO, Karakoç, TH, 2017. Exergetic and exergoeconomic assessment of a small-scale turbojet fuelled with biodiesel. Energy, 140, 1358-1367.

Dash JP, Watt MS, Pearse GD, Heaphy M, Dungey HS, 2017. Assessing very high resolution UAV imagery for monitoring forest health during a simulated disease outbreak. ISPRS Journal of Photogrammetry and Remote Sensing, 131, 1-14.

De Beni E, Cantarero M, Messina A, 2019. UAVs for volcano monitoring: A new approach applied on an active lava flow on Mt. Etna (Italy), during the 27 February-02 March 2017 eruption. Journal of Volcanology and Geothermal Research, 369, 250-262.

De Melo RRS, Costa DB, Álvares JS, Irizarry J, 2017. Applicability of unmanned aerial system (UAS) for safety inspection on construction sites. Safety science, 98, 174-185.

Dincer I, Rosen MA, 2012. Exergy: energy, environment and sustainable development. Newnes.

Goodchild A, Toy J, 2018. Delivery by drone: An evaluation of unmanned aerial vehicle technology in reducing $\mathrm{CO} 2$ emissions in the delivery service industry. Transportation Research Part D: Transport and Environment, 61, 58-67.

Hambrecht L, Brown RP, Piel AK, Wich SA, 2019. Detecting 'poachers' with drones: Factors influencing the probability of detection with TIR and RGB imaging in miombo woodlands, Tanzania. Biological conservation, 233, 109-117.

Hill AC, 2019. Economical drone mapping for archaeology: Comparisons of efficiency and accuracy. Journal of Archaeological Science: Reports, 24, 80-91.

Igwe IS, 2019. Off-Design Performance Analysis of Gbaran-Ubie Gas Power Plant, Bayelsa State, Using Energy and Exergy Methods. International Journal of Engineering Science, 21956. 

Thermodynamic Analysis

Iuga C, Drăgan P, Bușoniu L, 2018. Fall monitoring and detection for at-risk persons using a UAV. IFACPapersOnLine, 51(10), 199-204.

Ivushkin K, Bartholomeus H, Bregt AK, Pulatov A, Franceschini MH, Kramer H, ... Finkers R, 2019. UAV based soil salinity assessment of cropland. Geoderma, 338, 502-512.

Katariya M, Chung DCK, Minife T, Gupta H, Zahidi AAA, Liew OW, Ng TW, 2018. Drone inflight mixing of biochemical samples. Analytical biochemistry, 545, 1-3.

Kaya N, Turan Ö, Karakoç TH, Midilli A, 2016. Parametric study of exergetic sustainability performances of a high altitude long endurance unmanned air vehicle using hydrogen fuel. International Journal of Hydrogen Energy, 41(19), 8323-8336.

Kilani N, Khir T, Brahim AB, 2019. Energetic and Exergetic Optimization of a Combined Cycle Power Plant with Dual-Pressure HRSG, Compressed Air Cooling, Steam Injection and Vapor Extraction Systems. Iranian Journal of Science and Technology, Transactions of Mechanical Engineering, 43(1), 527-536.

Koruyucu E, 2019. Energy and exergy analysis at different hybridization factors for hybrid electric propulsion light utility helicopter engine. Energy, 189, 116105.

Krishnan EN, Balasundaran N, Thomas RJ, 2018. Thermodynamic analysis of an integrated gas turbine power plant utilizing cold exergy of LNG. Journal of Mechanical Engineering and Sciences, 12(3), 3961-3975.

Kumar NM, Sudhakar K, Samykano M, Jayaseelan V, 2018. On the technologies empowering drones for intelligent monitoring of solar photovoltaic power plants. Procedia computer science, 133, 585-593.

Langhammer J, Janský B, Kocum J, Minařík R, 2018. 3-D reconstruction of an abandoned montane reservoir using UAV photogrammetry, aerial LiDAR and field survey. Applied geography, 98, 9-21.

Lefebvre AH, Ballal DR, 2010. Gas Turbine Combustion: Alternative Fuels and Emissions, 3nd ed., CRC Press, London.

Liardon JL, Hostettler L, Zulliger L, Kangur K, Shaik NSG, Barry DA, 2018. Lake imaging and monitoring aerial drone. HardwareX, 3, 146-159.

Liu K, Shen X, Cao L, Wang G, Cao F, 2018. Estimating forest structural attributes using UAV-LiDAR data in Ginkgo plantations. ISPRS journal of photogrammetry and remote sensing, 146, 465-482.

Ludeno G, Catapano I, Renga A, Vetrella AR, Fasano G, Soldovieri F, 2018. Assessment of a micro-UAV system for microwave tomography radar imaging. Remote Sensing of Environment, 212, 90-102.

Malone M, Foster E, 2019. A mixed-methods approach to determine how conservation management programs and techniques have affected herbicide use and distribution in the environment over time. Science of The Total Environment, 660, 145-157.

Marmolejo-Correa D, Gundersen T, 2012. A new graphical representation of exergy applied to low temperature process design. In Computer aided chemical engineering (Vol. 31, pp. 1180-1184). Elsevier.

Mattingly JD, 2006. Elements of propulsion: gas turbines and rockets. American Institute of Aeronautics and Astronautics.

McCall B, 2019. Sub-Saharan Africa leads the way in medical drones.

Narayanan RGL, Ibe OC, 2015. Joint Network for Disaster Relief and Search and Rescue Network Operations. In Wireless Public Safety Networks 1 (pp. 163-193). Elsevier.

Rakha T, Gorodetsky A, 2018. Review of Unmanned Aerial System (UAS) applications in the built environment: Towards automated building inspection procedures using drones. Automation in Construction, 93, 252264.

Rossini M, Di Mauro B, Garzonio R, Baccolo G, Cavallini G, Mattavelli M, ... Colombo R, 2018. Rapid melting dynamics of an alpine glacier with repeated UAV photogrammetry. Geomorphology, 304, 159-172.

Roth BA, Mavris DN, 2000. A comparision of thermodynamic loss models applied to the J-79 turbojet engine. Joint Propulsion Conference and Exhibit, 36th, Huntsville, July, Alabama, USA, AIAA2000-3715.

Rusnák M, Sládek J, Kidová A, Lehotský M, 2018. Template for high-resolution river landscape mapping using UAV technology. Measurement, 115, 139-151. 

Thermodynamic Analysis

Salvo G, Caruso L, Scordo A, 2014. Urban traffic analysis through an UAV. Procedia-Social and Behavioral Sciences, 111, 1083-1091.

Sanaye S, Amani M, Amani P, 2018. 4E modeling and multi-criteria optimization of CCHPW gas turbine plant with inlet air cooling and steam injection. Sustainable Energy Technologies and Assessments, 29, 70-81.

Senthilnath J, Kandukuri M, Dokania A, Ramesh KN, 2017. Application of UAV imaging platform for vegetation analysis based on spectral-spatial methods. Computers and Electronics in Agriculture, 140, 8-24.

Seo J, Duque L, Wacker J, 2018. Drone-enabled bridge inspection methodology and application. Automation in Construction, 94, 112-126.

Singha A, Ray AK, Samaddar AB, 2018. Trajectory tracking in the desired formation around a target by multiple uav systems. Procedia Computer Science, 133, 924-931.

Stek TD, 2016. Drones over Mediterranean landscapes. The potential of small UAV's (drones) for site detection and heritage management in archaeological survey projects: A case study from Le Pianelle in the Tappino Valley, Molise (Italy). Journal of Cultural Heritage, 22, 1066-1071.

Sutheerakul C, Kronprasert N, Kaewmoracharoen M, Pichayapan P, 2017. Application of unmanned aerial vehicles to pedestrian traffic monitoring and management for shopping streets. Transportation research procedia, 25, 1717-1734.

Şöhret Y, Dinç A, Karakoç TH, 2015. Exergy analysis of a turbofan engine for an unmanned aerial vehicle during a surveillance mission. Energy, 93, 716-729.

Şöhret, Y. (2018a). Ecologic performance and sustainability evaluation of a turbojet engine under on-design conditions. Aviation, 22(4), 166-173.

Şöhret, Y. (2018b). Exergo-sustainability analysis and ecological function of a simple gas turbine aero-engine. Journal of Thermal Engineering (JTEN), 4(4), 2083-2095.

Turan Ö, Aydin H, 2016. Numerical calculation of energy and exergy flows of a turboshaft engine for power generation and helicopter applications. Energy, 115, 914-923.

Valkaniotis S, Papathanassiou G, Ganas A, 2018. Mapping an earthquake-induced landslide based on UAV imagery; case study of the 2015 Okeanos landslide, Lefkada, Greece. Engineering geology, 245, 141-152.

Verfuss UK, Aniceto AS, Harris DV, Gillespie D, Fielding S, Jiménez G, ... Storvold R, 2019. A review of unmanned vehicles for the detection and monitoring of marine fauna. Marine pollution bulletin, 140, 1729.

Wang X, Sun H, Long Y, Zheng L, Liu H, Li M, 2018. Development of Visualization System for Agricultural UAV Crop Growth Information Collection. IFAC-PapersOnLine, 51(17), 631-636.

Wang Z, Griffin AS, Lucas A, Wong KC, 2019. Psychological warfare in vineyard: Using drones and bird psychology to control bird damage to wine grapes. Crop Protection, 120, 163-170.

Xia J, Wang K, Wang S, 2019. Drone scheduling to monitor vessels in emission control areas. Transportation Research Part B: Methodological, 119, 174-196.

Zakeri H, Nejad FM, Fahimifar A, 2016. Rahbin: A quadcopter unmanned aerial vehicle based on a systematic image processing approach toward an automated asphalt pavement inspection. Automation in Construction, $72,211-235$.

Zhang J, Hu J, Lian J, Fan Z, Ouyang X, Ye W, 2016. Seeing the forest from drones: Testing the potential of lightweight drones as a tool for long-term forest monitoring. Biological Conservation, 198, 60-69.

Zheng X, Wang F, Li Z, 2018. A multi-UAV cooperative route planning methodology for 3D fine-resolution building model reconstruction. ISPRS journal of photogrammetry and remote sensing, 146, 483-494. 